\title{
Molecular mechanisms of human herpes viruses inferring with host immune surveillance
}

\author{
Simon Jasinski-Bergner (D) , ${ }^{1}$ Ofer Mandelboim (D) ,2 Barbara Seliger ${ }^{1}$
}

To cite: Jasinski-Bergner $\mathrm{S}$, Mandelboim 0, Seliger B. Molecular mechanisms of human herpes viruses inferring with host immune surveillance. Journal for ImmunoTherapy of Cancer 2020;8:e000841. doi:10.1136/jitc-2020-000841

Accepted 03 June 2020

Check for updates

(C) Author(s) (or their employer(s)) 2020. Re-use permitted under CC BY-NC. No commercial re-use. See rights and permissions. Published by BMJ.

${ }^{1}$ Institute for Medical Immunology, Martin-LutherUniversitat Halle-Wittenberg, Halle (Saale), Germany ${ }^{2}$ Immunology \& Cancer Research Center, Hebrew University of Jerusalem, Jerusalem, Israel

Correspondence to Dr Simon Jasinski-Bergner; simon.jasinski@uk-halle.de

\begin{abstract}
Several human herpes viruses (HHVs) exert oncogenic potential leading to malignant transformation of infected cells and/or tissues. The molecular processes induced by viral-encoded molecules including microRNAs, peptides, and proteins contributing to immune evasion of the infected host cells are equal to the molecular processes of immune evasion mediated by tumor cells independently of viral infections. Such major immune evasion strategies include (1) the downregulation of proinflammatory cytokines/chemokines as well as the induction of anti-inflammatory cytokines/chemokines, (2) the downregulation of major histocompatibility complex (MHC) class la directly as well as indirectly by downregulation of the components involved in the antigen processing, and (3) the downregulation of stress-induced ligands for activating receptors on immune effector cells with NKG2D leading the way. Furthermore, (4) immune modulatory molecules like MHC class Ib molecules and programmed cell death1 ligand 1 can be upregulated on infections with certain herpes viruses. This review article focuses on the known molecular mechanisms of HHVs modulating the above-mentioned possibilities for immune surveillance and even postulates a temporal order linking regular tumor immunology with basic virology and offering putatively novel insights for targeting HHVs.
\end{abstract}

\section{INTRODUCTION}

The molecular mechanisms of virus-related malignant transformation of non-tumorous tissues are diverse and involve molecules encoded by viruses or induced on viral infection. Viruses are able to infect all types of life forms such as animals, plants, fungi, protists, and even microorganisms, like yeast, bacteria, and archaea. ${ }^{1-5}$ Viral infections can predispose a patient to various malignancies which might be mediated by oncogenic viruses like Epstein-Barr virus (HHV4, EBV), human herpes virus 8 (HHV8, Kaposi-Sarkom herpes virus (KSHV)), hepatitis B virus, and certain human papilloma viruses (HPV).

Viruses completely rely on the host cell machinery to propagate and lack an own metabolism and reproduction. The viral particles, also called virions, contain the genetic material (single-stranded/double-stranded (ss/ds) RNA or ss/dsDNA), a protein coat (capsid) and optional a lipid envelope. The space between the lipid envelope derived from the host cell membranes and the capsid is the tegument, which contains molecules from the infected host cell including, for example, proteins and non-coding RNA species. These molecules may originate from the host cell or by the viruses of the infected host cell and promote the generation of macromolecules required for the next infection cycle. ${ }^{6}$ Furthermore, the tegument contains fluids of the cytoplasm, the endoplasmic reticulum (ER) and/or of the Golgi apparatus. ${ }^{78}$

In ER, the assembly of the classical major histocompatibility complex (MHC) class Ia and non-classical MHC class Ib molecules consisting of the MHC class Ia/b heavy chain (HC), $\beta_{2}$-microglobulin $\left(\beta_{2}-\mathrm{m}\right)$, and a peptide derived from cellular proteins, which could theoretically also represent peptides derived from viral proteins or in the case of malignant transformed cells also from tumor antigens. The peptides are generated and processed by different components of the antigen processing and presentation machinery (APM) for their presentation to $\mathrm{CD}^{+}$cytotoxic T lymphocytes (CTLs) on the cell surface. 910

The MHC class Ia molecules are physiologically expressed in nucleated cells with the exception of immune privileged tissues like cornea, brain, testis and chorion. In contrast, the MHC class Ib molecules, predominantly HLA-G and HLA-E, exert a physiologically restricted and tightly regulated expression exclusively in immune privileged tissues. ${ }^{11} 12$ Since MHC class Ib molecules represent potent ligands for inhibitory receptors of immune effector cells, the modulation of these molecules has functional relevance for immune responses. ${ }^{13} 14$

Independently of viral infections in solid and hematopoietic tumor diseases, classical MHC class Ia molecules are downregulated 
with high frequencies by equal strategies, while nonclassical MHC class Ib molecules are induced, and even secreted or shedded into the local tumor microenvironment (TME) strongly contributing to the tumor immune escape. ${ }^{11}$

Next to antigen presentation toward CTLs, also other molecular mechanisms contribute to successful immune surveillance against viral infections. Despite primary virus infections could elicit host antiviral immune responses, these responses are often insufficient to eliminate the virus. Thus, the ability of viruses to persist suggests that the viruses could subvert antiviral immune responses. For example, the virus mediated reduced expression of NKG2D ligands (NKG2D-Ls) upon viral infection avoids antiviral immune responses of the host immune system. ${ }^{15-19}$

In addition, the secretion of certain cytokines and/or chemokines on herpes virus infection is altered, which can modulate a strong and effective antiviral immune response against infected cells and/or tissues. It is noteworthy that a number of inhibitory mechanisms mediated by certain herpes viruses have been identified, which prevent the secretion of proinflammatory cytokines or enhance the secretion of anti-inflammatory cytokines. ${ }^{20}$ Furthermore, the expression and the assembly of MHC class Ia/b and/or APM molecules and the NKG2D-Ls can be induced or reduced by different cytokines.

In this review, the known immune escape mechanisms of human herpes viruses (HHVs) are summarized. The family of dsDNA herpes viruses consists of the $\alpha$-subfamily (herpes simplex virus, HSV-1, HSV-2, varicellazoster virus $(\mathrm{VZV}))$, the $\beta$-subfamily (cytomegalovirus (CMV), HHV6A, HHV6B, HHV7), and the $\gamma$-subfamily (EBV, KSHV), which exerts an oncogenic potential. This separation is based on their host range, genetic organization and replication strategies. ${ }^{21}$ These family members share a common viral morphology and approximately 40 conserved genes important for viral replication. ${ }^{22}$ Nevertheless, these pathogens differ in their pathogenicity. While the members of the $\alpha$-subfamily have been identified to act as cofactors for some tumor malignancies resulting in elevated tumor incidences, the members of the $\gamma$-subfamily are causative inductors of solid and hematopoietic tumor diseases. Furthermore, CMV as a member of the $\beta$-subfamily may infect critical organs including the nervous system, hematological and vascular system, gastrointestinal system and therefore may be accompanied by severe disease outcome in apparently healthy individuals. $^{23}$

Following a primary infection, it is characteristically for herpes viruses to persist in the host for an extended duration, considering the herpes viruses as highly successful pathogens. ${ }^{24}$ A contributing factor of the herpes viruses is their ability to adopt two different modes of life cycle: the latency and the lytic cycles. After such a primary productive infection, the herpes viruses switch to latency, a transcriptional and translational suppressed state. This latent state can be frequently interrupted by lytic episodes. During such latency, the latency-associated transcripts including coding transcripts resulting in viral peptides and proteins as well as non-coding transcripts like microRNAs (miRs) have been identified to contribute to immune evasion. ${ }^{24-27}$

Focusing on the MHC class I a/b molecules, APM components, NKG2D-Ls, cytokine and chemokine signaling on viral infection, this review article will highlight the known interfering molecular mechanisms of viral encoded or induced miRs, peptides and proteins. Exactly such processes are affected in tumor cells, also shaping the composition of the TME and therefore representing fundamental steps in immune surveillance or immune escape. Thus, the direct interactions between viral molecules of HHVs and host cell molecules next to indirect mechanisms leading to the induction/reduction of relevant host cell factors on viral infection will be addressed and discussed.

\section{VIRAL PROTEINS INTERFERE WITH THE PEPTIDE PRESENTATION OF MHC CLASS I MOLECULES}

Under physiologic conditions, the assembled trimeric MHC class I molecules consisting of the MHC class I HC, non-covalent bound $\beta_{2}-m$, and processed peptides of $8-12$ amino acids in length are transported via the trans-Golgi to the cell surface of nucleated cells and presented to CD8 $^{+}$CTLs. ${ }^{11}$

After ubiquitination, cellular proteins are degraded into peptides by the multicatalytic proteasome with a correct C-terminus, but a relegated N-terminus. These peptides could be further trimmed by cytosolic or ER-resident aminopeptidases. ${ }^{28}$ The cytokine interferon (IFN)- $\gamma$ induces the so-called immunoproteasome, which contains novel active subunits of the proteasome activator (PA) 28 and the IFN- $\gamma$-inducible proteasomal $\beta$-subunits, the low molecular weight proteins (LMP)2, MECL1 and LMP7, replacing their constitutive homologs $\beta 1, \beta 2$, and $\beta 5$ during proteasome assembly. ${ }^{29}$ During the initial viral infection, a rapid induction of the immunoproteasome is crucial, which leads to an altered peptide repertoire. ${ }^{30}$ Subsequently, the peptides are transported via the heterodimeric transporter associated with antigen processing (TAP)1/TAP2 into the ER, which forms a peptide loading complex with the chaperones calreticulin (CALR), tapasin (TPN) and the protein ERp57, thereby facilitating peptide loading onto MHC class I molecules non-cavalently bound to $\beta 2-\mathrm{m}$.

Reduced or impaired expression of any of these molecules can act as a bottleneck for proper MHC class I surface expression. For example, mutations or deletions of B2M or TAP subunits result in a complete absence of MHC class I molecules on the cell surface. ${ }^{31-34}$ Furthermore, downregulation of MHC class Ia surface levels on reduced expression of one or more APM components represents a potent mechanism for immune escape in tumor cells, but also of viral-infected cells to escape immune surveillance. However, in contrast to tumors, 
Table 1 Viral peptides/proteins as well as viral miRs targeting MHC class I and APM components

Targeted mechanisms for downregulation of MHC class I

\begin{tabular}{|c|c|c|c|c|}
\hline & $\begin{array}{l}\text { Peptide generation in } \\
\text { general }\end{array}$ & $\begin{array}{l}\text { Peptide transport in } \\
\text { general }\end{array}$ & $\begin{array}{l}\text { Peptide loading in } \\
\text { general }\end{array}$ & $\begin{array}{l}\text { MHC class I or } \\
\text { unknown reductive } \\
\text { mechanism }\end{array}$ \\
\hline Viral proteins/peptides & $\begin{array}{l}\text { vlL-10 }\left(\mathrm{EBV}^{39}\right) \\
\text { BGLF5 }\left(\mathrm{EBV}^{41}\right) \\
\text { EBNA-1 }\left(\mathrm{EBV}^{42}\right)\end{array}$ & $\begin{array}{l}\left.\text { ICP47 (HSV-1 }{ }^{3536}\right) \\
\text { BNLF2a }\left(\mathrm{EBV}^{38}\right) \\
\left.\text { vIL-10 (EBV }{ }^{39}\right) \\
\text { US6 }\left(\mathrm{CMV}^{44}\right)\end{array}$ & US3 $\left(\mathrm{CMV}^{45}\right)$ & $\begin{array}{l}\text { ORF66 }\left(\mathrm{VZV}^{37}\right) \\
\text { BILF1 }\left(\mathrm{EBV}^{40}\right) \\
\text { BDLF3 }\left(\mathrm{EBV}^{43}\right) \\
\text { US10 }\left(\mathrm{CMV}^{46}\right) \\
\text { US11 }\left(\mathrm{CMV}^{47}\right) \\
\text { US2 }\left(\mathrm{CMV}^{48}\right) \\
\text { U21 }\left(\mathrm{HHV}^{51}\right) \\
\text { K3 }\left(\mathrm{KSHV}^{52}\right) \\
\left.\text { K5 (KSHV }{ }^{52}\right) \\
\text { LANA1 }\left(\mathrm{KSHV}^{53}\right)\end{array}$ \\
\hline Viral miRs & miR-US4-1 $\left(\mathrm{CMV}^{72}\right)$ & $\begin{array}{l}\text { miR-BART17 }\left(E^{2 B V}{ }^{71}\right) \\
\text { miR-BHRF1-3 }\left(E^{71}\right)\end{array}$ & n.d. & n.d. \\
\hline
\end{tabular}

APM, antigen processing and presentation machinery; CMV, cytomegalovirus; EBV, Epstein-Barr virus; KSHV, Kaposi-Sarkom herpes virus; MHC, major histocompatibility complex ; miRs, microRNAs; n.d., not determined; VZV, varicella-zoster virus.

many viral proteins have been identified to interfere with the expression of components of the APM. A summary of such 'immune evasions' is listed in table 1 .

The human herpes virus (HHV) 1 (herpes simplex virus 1, HSV-1) produces the protein ICP47 that blocks the peptide loading on the MHC class I HC by direct binding to the TAP $1 / 2$ heterodimer. ${ }^{35} 36$ In HHV-3 (VZV) infected cells, MHC class I complexes were hindered to pass through trans-Golgi to the cell surface, which is mediated by the VZV protein ORF66, ${ }^{37}$ while HHV-4 (EBV) encodes for the BNLF2a protein blocking the TAP 1/2 heterodimer even more efficient than ICP47 or US6. ${ }^{38}$ Furthermore, EBV encodes for the protein vIL-10, which downregulates TAP1 and LMP2 expression. Both genes are controlled by a bidirectional promoter. ${ }^{39}$ The EBV protein BILF1 reduces MHC class Ia surface expression, ${ }^{40}$ and the EBV protein BGLF5 as well as EBNA-1 interfere with the complete peptide generation. ${ }^{41} 42$ Interestingly, the late lytic BDLF3 gene product downregulates both MHC class I and class II molecules. ${ }^{43}$ The HHV-5 (cytomegalovirus, CMV) encodes for the US6 peptide, which is also able to interfere the peptide transport by blocking the TAP $1 / 2$ heterodimer. ${ }^{44}$ Additionally, CMV encodes for the US3 protein that inhibits the TPN-mediated peptide loading and therefore retains HLA class I molecules within the ER. ${ }^{45}$ While the US10 protein directly binds to MHC class I HC and retaining it in the ER, ${ }^{46}$ the US11 and US2 protein directs the MHC class I HC toward proteasomal degradation. ${ }^{48}$ Furthermore, it has been shown that the combination of cytosolic and ER-resident aminopeptidases shapes the pool of antigenic peptides as shown for the immunodominant CMV pp65495-503 CTL epitope. ${ }^{49}$ It is noteworthy that CMV virions can even bind $\beta_{2}-\mathrm{m}$ on the cell surface and might use it as receptor for virus entry. ${ }^{50}$
An immune evasion of the HHV-7 viruses is the inhibition of MHC class I presentation by the viral U21 protein. ${ }^{51}$ Furthermore, HHV-8 (KSHV) viruses express the $\mathrm{K} 3$ and $\mathrm{K} 5$ proteins leading to the downregulation of MHC class I molecules. ${ }^{52}$ The similar effect was also reported for LANA1. ${ }^{53}$

\section{VIRAL MICRORNAS PREVENT IMMUNE SURVEILLANCE BY MHC CLASS I MOLECULES}

Not only viral-encoded proteins can counteract immune surveillance by interfering with peptide processing and presentation of MHC class I molecules, also viral-encoded microRNAs (miRs) are reported to hinder the MHC class I mediated immune surveillance. miRs are small singlestranded non-coding RNAs of approximately 19-25 nucleotide (nt) in length ${ }^{54}$ binding sequence specifically to the $3^{\prime}$-untranslated region (UTR), but less frequent to the $5^{\prime}$-UTR and the coding sequence (CDS) of target mRNAs. ${ }^{55}$ The miR binding to the target mRNA results in translational inhibition leading to mRNA storage ${ }^{56}$ or in most cases to mRNA decay. ${ }^{57}$ Only the seed regions of the miRs between the second to seventh nt exert perfect complementary sequence homology to the target mRNA sequences, but the impact of their length and the resulting target repression is currently controversially discussed. ${ }^{58}$ Furthermore, miRs redundantly regulate mRNAs and one single miR may control the fate of many different target mRNAs. ${ }^{57}$

Some of the miRs affect tumor biologic relevant cellular functions, like cell proliferation, cell migration, invasion, angiogenesis, apoptosis inducibility, immune cell recognition and others. Therefore, based on their target genes, some miRs can be grouped into oncogenic, tumor suppressive or immune modulatory miRs. ${ }^{59}$ 
Interestingly, some of these miRs are functionally incorporated into the RNA-induced silencing complex (RISC) complex. ${ }^{60}$ So far, more than 250 viral miRs have been identified, predominantly encoded by herpes viruses, but also by polyomaviruses, ascoviruses, and adenoviruses. ${ }^{61}$ Herpes viruses encode and express not only own miRs binding to certain host mRNAs, they further alter the whole host cell miR transcriptome on infection ${ }^{61}$ and/ or during the process of viral-induced malignant transformation. ${ }^{62}$ In the case of EBV, the viral-mediated induction of the oncogenic miR-155 in host B cells is one major molecular mechanism for immortalization and malignant transformation. ${ }^{63}{ }^{64}$ On the other hand, the EBVencoded miR-BART-1 targets the tumor suppressor gene PTEN, which is associated with tumor metastasis. ${ }^{65}$ The viral miR BART16 targets the transcriptional coactivator CREBBP mRNA and thereby inhibits type I IFN signaling and other target genes of this important transcriptional coactivator, ${ }^{66}$ affecting the whole host cell transcriptome for a putative shift toward immortalization and malignant transformation. If secreted factors, like hormones, cytokines, and chemokines, are affected on viral infection, an impact even on non-infected host cells/tissues/ organs including immune effector cells could be possible. Indeed, KSHV downregulates the tumor suppressive miRs miR-221, miR-222, and the let7 family members of the infected host cell. ${ }^{67}$

The herpes viruses express miRs during the lytic phase and even during the latency. ${ }^{68}$ Currently, the tumor biologic and tumor immunologic targets of these viral miRs are identified. So far, there is no proof that the viruses do encode for additional miR processing enzymes or for additional RISC components, since the viralencoded miRs use the miR processing machinery of the infected host cells. ${ }^{70}$

Furthermore, EBV targets the mRNA of TAP2 by miRBART17 and miR-BHRF1-3. ${ }^{71}$ The CMV virus encodes for miR-US4-1 negatively regulating the ER-resident aminopeptidase ERAP1 involved in the peptide shaping/trimming for later presentation on MHC class I molecules. ${ }^{72}$ It is postulated that more herpes virus-encoded miRs will be identified impairing the function of the MHC class I APM in the future. All so far reported viral-encoded proteins and regulatory miRs affecting the MHC class I-mediated antigen presentation are summarized in table 1 .

\section{VIRAL PROTEINS RESTRAIN THE ACTIVITY OF IMMUNE EFFECTOR CELLS}

The current research does not only proof the inhibition of the MHC class I-dependent antigen presentation by viral proteins, but rather the disruption of the interaction between (infected/tumor) target cell and immune effector cells. Such disruption could be arranged by reduction of certain host cell proteins acting as ligands for activating receptors on immune effector cells or by enhancing the expression of viral and/or host molecules leading to the inhibition of immune effector cells. This includes an enhanced expression of immune modulatory molecules, like non-classical MHC class Ib molecules, in the host cell. Actually, the expression of non-classical MHC class Ib molecules is strongly induced in solid and hematopoietic tumor malignancies offering a strong mechanism for immune evasion. ${ }^{13}$

Indeed, HHV-1 induces HLA-G expression on infection in human neuronal cells. ${ }^{73}$ While HLA-G is a ligand for the inhibitory receptors ILT-2, ILT-4, and KIR2DL4, which are present on NK cells, CTLs, B cells, macrophages and dendritic cells, ${ }^{74}$ HLA-E binds to the inhibitory receptors CD94/NKG2A, -B and -C on NK cells and CTLs. ${ }^{75}$ For both immune modulatory molecules, a strictly controlled gene expression has been reported, which includes also miRs. Those HLA-G negative regulatoring miRs were also classified as tumor suppressive miRs ${ }^{137677}$ and might also be downregulated on viral infections. Indeed, CMV infection interferes the regulation between miR-376a and HLA-E. ${ }^{71}$ Furthermore, the HCMV genome encodes for different NK cell modulators, like UL135, UL141, UL142, and UL148 thereby inhibiting NK cell activation and recognition. ${ }^{78}$ UL141 inhibits the expression of the activating ligands $\mathrm{CD} 155$ and $\mathrm{CD} 112$, the activating receptor CD226 (DNAM-1), TRAIL-R1 and -R2, while UL142 and UL148A target specifically MICA and UL148 the expression of LFA-3.

Next to the viral-mediated enhancement of MHC class Ib molecules, the checkpoint molecule programmed cell death1 ligand 1 (PD-L1) is induced on several viral infections including HIV, HCV, and HHV1. ${ }^{79} 80$ There exist more immune inhibitory molecules, which are directly or indirectly induced on viral infections. For example, HHV1 induces transforming growth factor- $\beta$ (TGF- $\beta$ ) secretion of infected host cells. ${ }^{81}$ TGF- $\beta$ induces among others HLA-G, but inhibits MHC class Ia and APM components gene expression. ${ }^{82}$ Such mechanisms are strongly required for the further processes of viral infection and immune evasion.

A second strategy is the reduced expression of molecules that act as ligands for activating immune cell receptors including among others different NKG2D-Ls, namely the major histocompatibility complex class I-related molecules (MIC) A and B as well as the UL16-binding proteins (ULBP) 1-6, also known as retinoic acid early transcript 1 (RAET1) proteins. ${ }^{83} 84$ In analogy to the tightly controlled cell surface expression of the MHC class Ia/b molecules, the NKG2D-Ls exert also strongly regulated cell surface expression to avoid respective immune responses by NKG2D expressing NK cells and CTLs. ${ }^{85} 86$ Various pathophysiological situations, such as viral infection, oxidative stress, genotoxic drugs, tissue damage, heat shock, inflammatory cytokines, and malignant transformation are known inductors for NKG2D-L surface expression. ${ }^{59}$

HHV-1-infected cells show reduced surface levels of MICA and ULBP2 $2{ }^{87}$ as well as ULBP1 and $-3 .{ }^{88}$ VZV-infected cells reported to show equal effects by downregulating ULBP2 and ULBP3. ${ }^{88}$ EBV infection decreased MICA, MICB, and ULBP4 surface levels. ${ }^{89}$ 
Table 2 Viral peptides/proteins as well as viral miRs and other mechanisms leading to downregulation of the NKG2D ligands

\begin{tabular}{|c|c|c|c|c|c|c|c|c|}
\hline & \multicolumn{8}{|l|}{ NKG2D ligands } \\
\hline & MICA & MICB & ULBP1 & ULBP2 & ULBP3 & ULBP4 & ULBP5 & ULBP6 \\
\hline $\begin{array}{l}\text { Viral proteins/ } \\
\text { peptides }\end{array}$ & $\begin{array}{l}\text { UL142 } \\
\left(\mathrm{CMV}^{92}\right) \\
\text { US18 }\left(\mathrm{CMV}^{94}\right) \\
\text { US20 } \\
\left(\mathrm{CMV}^{94}\right) \\
\text { U21 } \\
\left(\mathrm{HHV}-7^{95}\right) \\
\text { K5 } \\
\left(\mathrm{KSHV}^{96}\right)\end{array}$ & $\begin{array}{l}\text { UL-16 }\left(\mathrm{CMV}^{91}\right) \\
\text { U21 } \\
\left(\mathrm{HHV}-7^{95}\right) \\
\text { K5 } \\
\left(\mathrm{KSHV}^{96}\right)\end{array}$ & $\begin{array}{l}\text { UL-16 } \\
\left(\mathrm{CMV}^{90}\right) \\
\text { U21 } \\
\left(\mathrm{HHV}-7^{95}\right)\end{array}$ & $\begin{array}{l}\text { UL-16 } \\
\left(\mathrm{CMV}^{90}\right)\end{array}$ & $\begin{array}{l}\text { UL142 } \\
\left(\mathrm{CMV}^{93}\right)\end{array}$ & n.d. & $\begin{array}{l}\text { UL-16 } \\
\left(\mathrm{CMV}^{90}\right)\end{array}$ & $\begin{array}{l}\text { UL-16 } \\
\left(\mathrm{CMV}^{90}\right)\end{array}$ \\
\hline viral miRs & $\begin{array}{l}\text { miR-BART7 } \\
\left(\mathrm{EBV}^{100}\right)\end{array}$ & 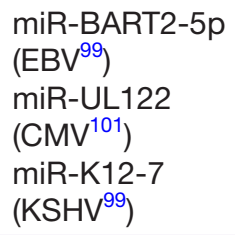 & n.d. & $\begin{array}{l}\text { miR-H8 } \\
\left(\mathrm{HSV}-1^{98}\right)\end{array}$ & $\begin{array}{l}\mathrm{miR}-\mathrm{H} 8 \\
\left(\mathrm{HSV}-1^{98}\right)\end{array}$ & n.d. & n.d. & n.d. \\
\hline
\end{tabular}

CMV, cytomegalovirus; EBV, Epstein-Barr virus; HSV-1, herpes simplex virus 1; KSHV, Kaposi-Sarkom herpes virus; miRs, microRNAs; n.d., not determined; VZV, varicella-zoster virus.

The many possibilities of the herpes viruses to downregulate NKG2D-L surface expression include viral-encoded proteins, binding to the NKG2D-Ls and causing a functional inhibition as well as viral miRs or a combination of them.

The CMV encodes for the UL16 protein, which is able to bind many ULBPs with the exception of ULBP3 and ULBP4. ${ }^{90}$ Even MICB can be bound and retained by UL16. ${ }^{91}$ Next to UL16, the viral UL142 protein binds and retains MICA as well as ULBP3. ${ }^{92} 93$ MICA is further targeted by the CMV gene products US18 and US20. ${ }^{94}$ The immune evasion by U21 of HHV7 not only inhibits MHC class I antigens, but it also contributes to the downregulation of MICA, MICB, and ULBP1. ${ }^{95}$ Furthermore, the KSHV protein K5 causes a downregulation of MICA and MICB. ${ }^{96}$ The viral proteins/peptides targeting NKG2D-L mRNAs are summarized in table 2.

\section{VIRAL-ENCODED MIRS ENABLE IMMUNE EVASION BY TARGETING NKG2D-L TRANSCRIPTION}

In analogy to the prevention of the antigen presentation by MHC class I molecules, the herpes viruses can also block the NKG2D-Ls via the expression of miRs. Indeed, current studies identified a number of viral miRs directly targeting the NKG2D-Ls or indirectly leading to a reduction of their surface levels. In addition, various host cellencoded oncogenic miRs have been described, which can be induced after malignant transformation or as an indirect result of viral infection, such as miR-17-5 p, miR-20a, miR-93 directed against MICA, miR-10b against MICB, and miR-650 against ULBP1. ${ }^{59}$ The literature even lists more human miRs targeting NKG2D-Ls, but these miRs have not yet been classified as oncogenic based on their functional activity.

In addition to these host cell miRs, the viral miR EBVmiR-BART-6 directly targets Dicer in the host cells, ${ }^{97}$ which has an impact on the whole miR transcriptome in the host cell and even on the processing of viral encoded miRs themselves. HHV-1 encodes for miR-H8, which reduces the surface levels of ULBP2 and ULBP3. ${ }^{98}$ The EBV-miRBART2-5p directly targets MICB, ${ }^{99}$ while EBV-miR-BART7 targets MICA. ${ }^{100}$ MICB expression is also repressed by the CMV-miR-UL122 ${ }^{101}$ and by KSHV-miR-K12-7. ${ }^{99}$ The viral encoded miRs targeting NKG2D-L mRNAs are summarized in table 2 .

\section{HERPES VIRUS-MEDIATED INTERFERENCE OF THE INTERACTION BETWEEN INFECTED HOST CELLS AND IMMUNE EFFECTOR CELLS BY TARGETING HOST CELL CYTOKINES AND CHEMOKINES}

For an early antiviral response, the secretion of certain proinflammatory cytokines is required, including among others IFN- $\gamma$, TNF- $\alpha$, IL-1 $\beta$, IL-2, IL-6, IL-12, IL- 18 , and IL-23, ${ }^{102-105}$ leading to the activation of phagocytic cells like macrophages, but also to the activation of CTLs and NK cells. As a consequence of these proinflammatory cytokines, proinflammatory chemokines, like CXCL-8, CCL2 (MCP-1), CCL3, CCL4, CCL5 (Rantes), CCL11, CXCL10, are released and recruit other immune effector cells. ${ }^{106} \mathrm{~A}$ viral intervention at this point is crucial and is to be affiliated functionally and temporally before CTLs interact with MHC class I presented antigens or NK cells interact with the infected cell via NKG2D-Ls and/or other molecules. This putative intervention may include the 
block of proinflammatory cytokines/chemokines and/or the increased secretion of anti-inflammatory cytokines/ chemokines. A respective summary of targeted cytokines and chemokines is listed in table 3 .

HHV-1 represses several proinflammatory cytokines, including IL-6, TNF- $\alpha$, IFN- $\alpha / \beta$, CCL5 (Rantes), and IL-12, IL-23 by the tegument localized proteins VP16, ICP4 and ICP27, ${ }^{107}$ which underlines the relevance of these molecules for an early immune evasion.

EBV inhibits the IFN- $\gamma$ downstream signaling pathway by its immediate-early protein BZLF $1 .{ }^{108}$ Furthermore, EBV lytic transactivator Zta was characterized as a potent suppressor of IFN- $\beta$ production, ${ }^{109}$ while the EBV LMP1 protein inhibits TNF- $\alpha .{ }^{110}$ The EBV protein LMP1 induces the secretion of the anti-inflammatory cytokine IL-10, ${ }^{111}$ whereas the EBV miR-BHRF1-2-5p blocks the proinflammatory IL-1 signaling. ${ }^{112}$

CMV disrupts multiple levels of the IFN- $\alpha$ signal transduction pathwayy ${ }^{113}$ and the IFN- $\beta$ response with its US9 protein. ${ }^{114}$ Also targeting the TNF- $\alpha^{115}$ as well as the IFN- $\gamma$ induced gene expression by the CMV-encoded protein UL23 has been reported. ${ }^{116}$

The $\beta$-subfamily and $\gamma$-subfamily of the herpes viruses encode for own viral chemokines and even viral chemokine receptors known to bind and interfere with the functions of the host cell chemokines. ${ }^{117}$ The CMV UL21.5 mRNA is also packed within the virion, and its protein binds and blocks the function of CCL5 (Rantes), ${ }^{118}$ whereas the CMV-encoded protein US28 blocks CCL5 function. ${ }^{119} \mathrm{KSHV}$ expresses the viral chemokine vCCL2, which is a broad-spectrum chemokine receptor antagonist, which might impair the recruitment of antiviral immune cells to the site of infection. ${ }^{117}{ }^{120}$ The KSHV infection is further accompanied by a reduced secretion of TNF- $\alpha$ and IL- $1 .{ }^{121}$

\section{CONCLUSION}

This review summarizes for the first time the combined mechanisms for immune evasion strategies of herpes viruses with focus on cytokine/chemokine signaling, thereby interfering the MHC class I-mediated antigen presentation and the interaction with immune effector cells via NKG2D-L (figure 1). While the cytokine/ chemokine signaling and the NKG2D-based interactions reflect parts of the innate immunity also, the adaptive immunity is targeted by viral molecules including antigen processing and presentation via MHC class I molecules. It is noteworthy that also other subareas of the immune system are targeted by viral molecules encoded by HHVs that have not been addressed within this study.

The cytokine/chemokine signaling is a very early reaction to viral infection and might explain the presence of the respective inhibiting viral factors in the tegument. Such factors are present as protein encoding mRNAs or already as peptides/proteins. In the case of viral-based cytokine and chemokine inhibition, the

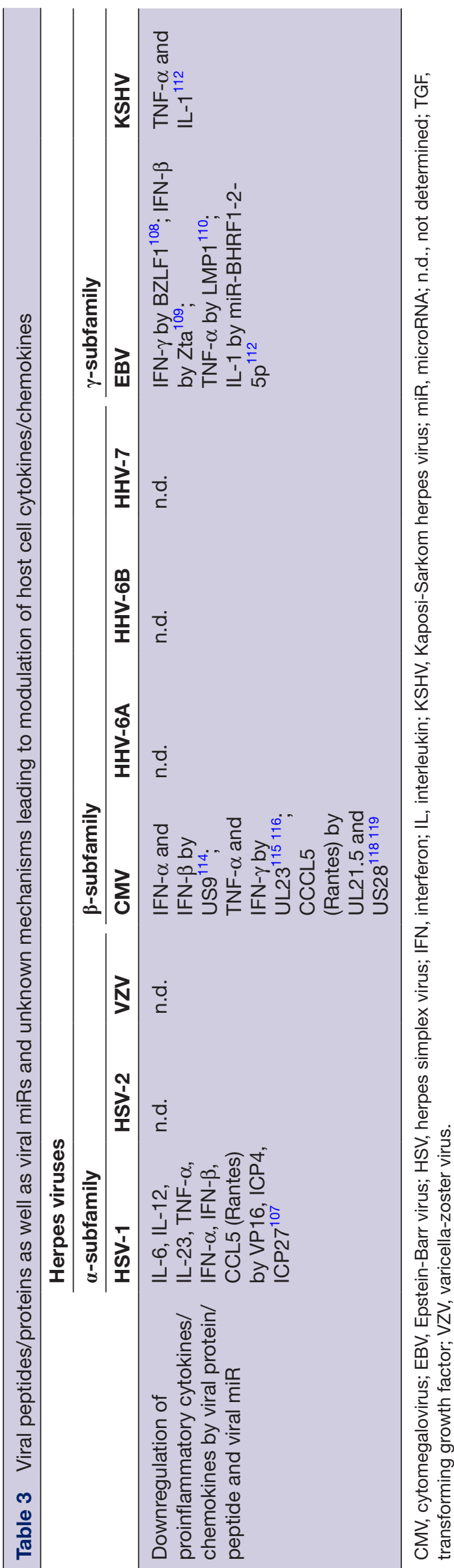




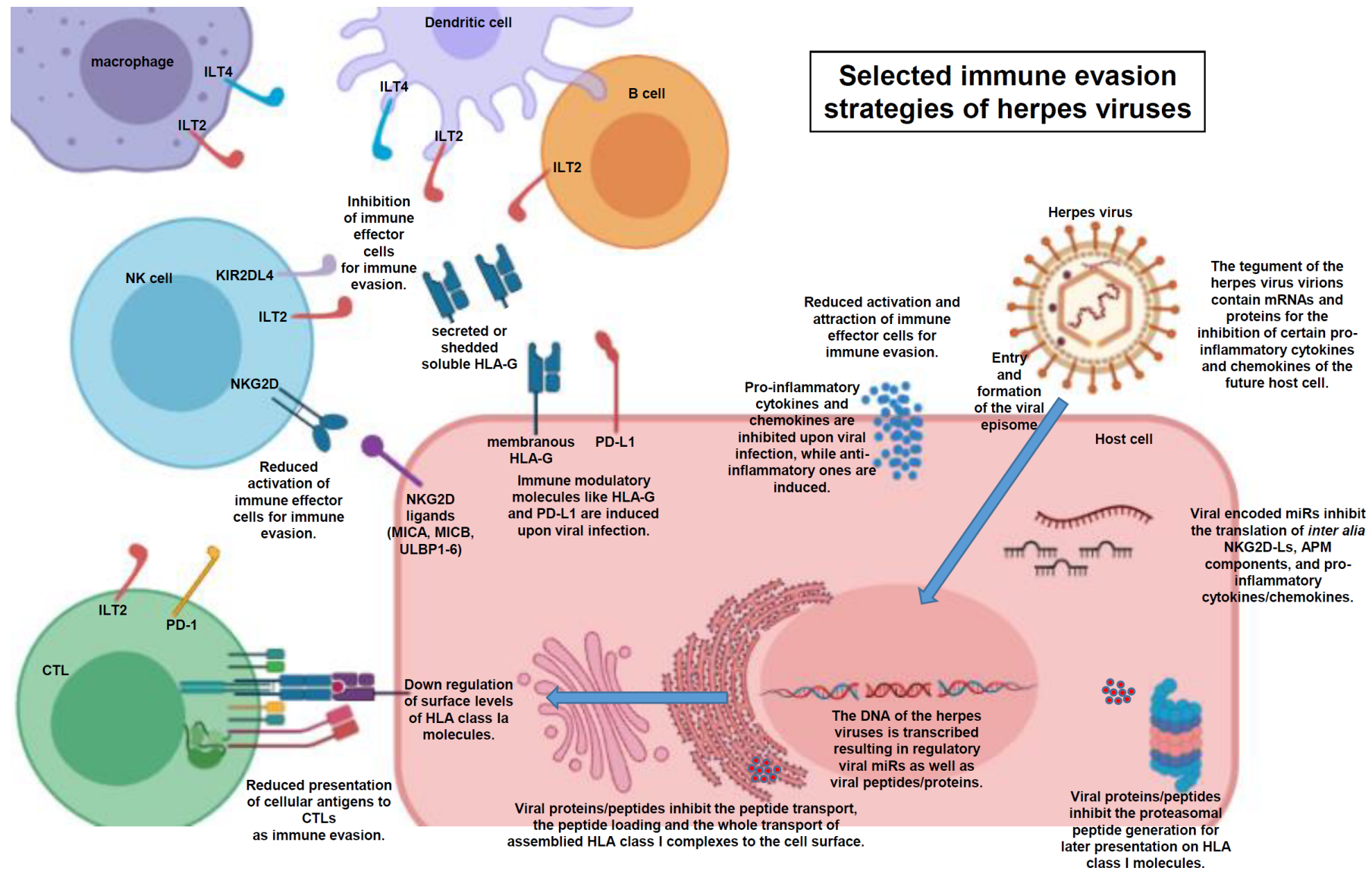

Figure 1 Selected immune evasion strategies of herpes viruses in the cellular context of infected host cell and immune effector cells. APM, antigen processing and presentation machinery; CTLs, cytotoxic T lymphocytes; HLA, human leukocyte antigen; IL, interleukin.

involvement of respective viral miRs is not yet well investigated. In contrast, the involvement of viral miRs as well as peptides/proteins in the different steps of the complex MHC class I-mediated antigen presentation as well as in the NKG2D-Ls-based immune effector cell interaction is well studied and understood. A temporal order in the establishment of the strategies enabling the immune evasion on infection with herpes viruses is summarized in figure 2 and highlights the downregulation of proinflammatory cytokines and/or chemokines as first step based on the fact that already the virions contain molecules directly targeting a proper cytokine and chemokine signaling. Only after host cell infection and viral DNA transcription leading to viral miRs and after translation of viral mRNAs to viral peptides and/or proteins, other mechanisms of correct immune surveillance are targeted including inter alia MHC class I antigen presentation as well as NKG2D interaction.

Unfortunately, only a little is known whether the reported molecular interactions between the viral miRs/peptides/proteins with immunological relevant targets in the host cell differ between primary infection, latency, reinfection, and so on, or whether they differ if different target cell types infected by the same virus, for example, EBV-infected B cells compared with infected epithelial cells of the respiratory tract. Further clinical studies are necessary to investigate and validate the clinical relevance of the reported in vitro studies.

Furthermore, it is important to consider the information of the viral-encoded immunomodulatory molecules in the context of coexpressed viral-encoded oncogenes. Already mentioned were the indirect mechanisms, like the induction of the human-encoded oncogenic miR-155 in host B cells by EBV. But, additionally, the herpes viruses are known to encode for genes exerting an oncogenic potential and such factors are not only limited to the strongly cancer-associated two members of the $\gamma$-subfamily of the human herpes viruses, namely, EBV and KSHV. In fact, even HSV-1 and HSV-2 are reported to act as cofactors for malignant transformation in several tumor malignancies including thyroid tumors, prostate cancer, and elevated incidences for melanoma, as well as cervical cancer in combination with HPV. ${ }^{122-125}$ As a major cause for a putative malignant transformation mediated by $\mathrm{HSV}-1 / 2$, the oncogenic and antiapoptotic viral protein ICP10PK is discussed. ${ }^{126} \mathrm{VZV}$ is also speculated to elevate the risk for certain malignancies mediated by its antiapoptotic IE63 protein. ${ }^{127} 128$ The oncogenic potential of EBV is well characterized. It is highly associated with the Burkitt's lymphoma, Hodgkin's lymphoma, and nasopharyngeal carcinoma. LMP1 was so far identified as 


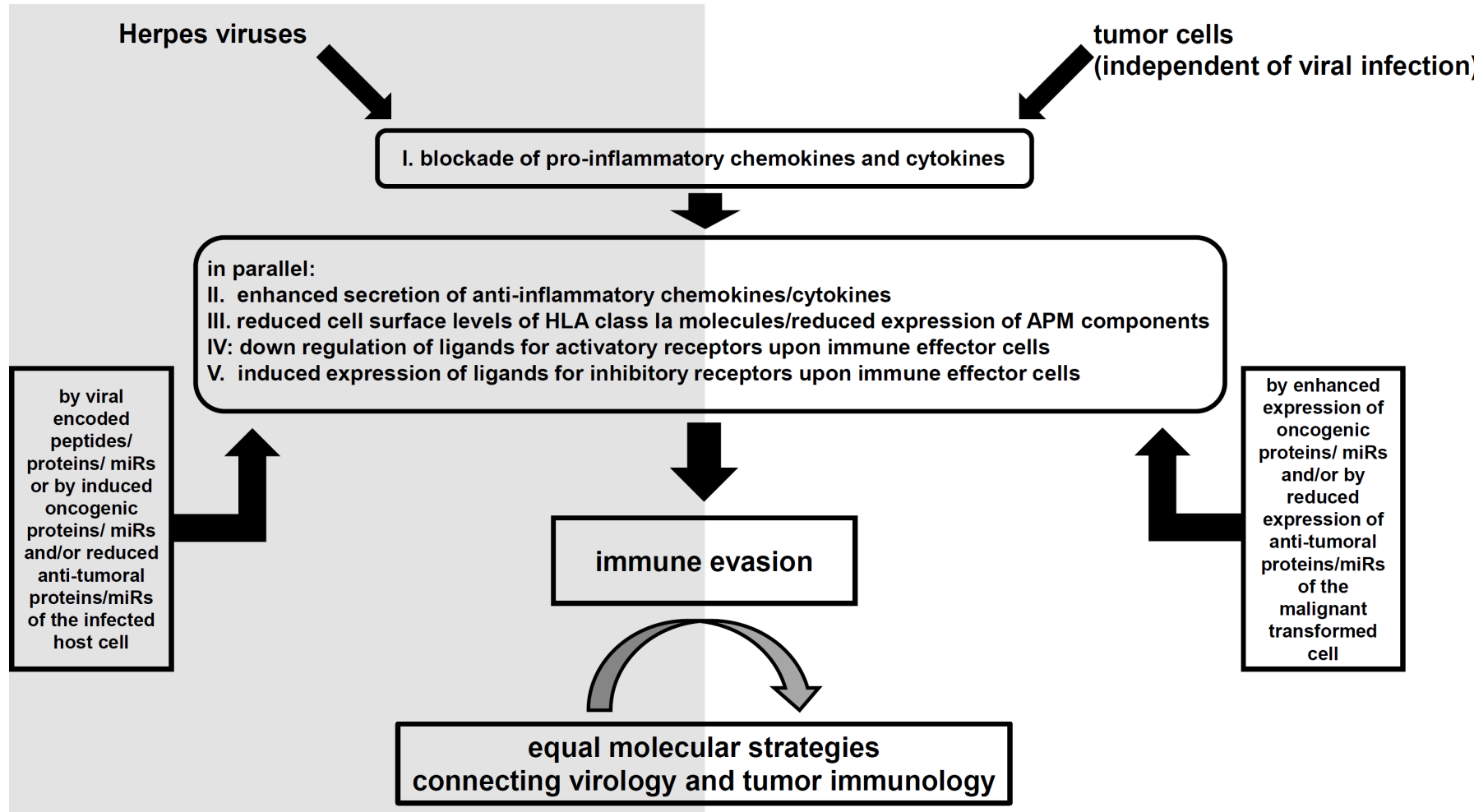

Figure 2 Schematic summary of the highlighted mechanisms leading to immune evasion with postulated temporal order. APM, antigen processing and presentation machinery; HLA, human leukocyte antigen; miR, microRNA.

the major EBV oncogene. ${ }^{129}$ The Roseoloviruses (HHV$6 / 7)$ were at least detected in some hematopoietic malignancies. ${ }^{130131}$ In contrast, the KSHV is the causative inductor of the Kaposi's sarcoma by inhibiting the apoptosis via the viral-encoded proteins LANA, viral Bcl-2, and K13. ${ }^{132} 133$ Many malignancies induced by the herpes viruses occur in combination with immune deficiencies. The ability of the herpes viruses to prevent complete elimination by the host immune system is therefore a possible neuralgic point for putative therapies.

All of the addressed mechanisms for immune surveillance are also targeted in tumor cells independently of viral infections and therefore the authors want to underline the strong connection between tumor immunology and virology.

Acknowledgements The authors want to thank Maria Heise and Nicole Ott for secretarial assistance. Figure 1 was created with BioRender.

Contributors SJ-B and BS designed the review article. SJ-B, OM, and BS wrote the manuscript.

Funding This work was funded by the German-Israeli Foundation (GIF; I-37414.11-2016) and Dr Werner Jackstädt Foundation.

Competing interests None declared.

Patient consent for publication Not required.

Provenance and peer review Not commissioned; externally peer reviewed.

Open access This is an open access article distributed in accordance with the Creative Commons Attribution Non Commercial (CC BY-NC 4.0) license, which permits others to distribute, remix, adapt, build upon this work non-commercially, and license their derivative works on different terms, provided the original work is properly cited, appropriate credit is given, any changes made indicated, and the use is non-commercial. See http://creativecommons.org/licenses/by-nc/4.0/.

\section{ORCID iDs}

Simon Jasinski-Bergner http://orcid.org/0000-0001-6300-7371

Ofer Mandelboim http://orcid.org/0000-0002-9354-1855

\section{REFERENCES}

1 Attar N. Viral evolution: animal viruses in pieces. Nat Rev Microbiol 2016;14:606-7.

2 Roossinck MJ. Metagenomics of plant and fungal viruses reveals an abundance of persistent lifestyles. Front Microbio/ 2014;5:767.

3 Berjón-Otero M, Koslová A, Fischer MG. The dual lifestyle of genome-integrating virophages in protists. Ann N Y Acad Sci 2019;1447:97-109.

4 Maaty WS, Steffens JD, Heinemann J, et al. Global analysis of viral infection in an archaeal model system. Front Microbiol 2012;3:411.

5 Brüssow $\mathrm{H}$. Bacteria between protists and phages: from antipredation strategies to the evolution of pathogenicity. Mol Microbiol 2007;65:583-9.

6 Amen MA, Griffiths A. Packaging of non-coding RNAs into herpesvirus virions: comparisons to coding RNAs. Front Genet 2011;2:81

7 Homman-Loudiyi M, Hultenby K, Britt W, et al. Envelopment of human cytomegalovirus occurs by budding into Golgi-derived vacuole compartments positive for $\mathrm{gB}, \mathrm{Rab} 3$, trans-Golgi network 46, and mannosidase II. J Virol 2003;77:3191-203.

8 Wild P, Kaech A, Schraner EM, et al. Endoplasmic reticulumto-Golgi transitions upon herpes virus infection. F1000Res 2017;6:1804.

9 Reeves E, James E. Antigen processing and immune regulation in the response to tumours. Immunology 2017;150:16-24.

10 Rock KL, Reits E, Neefjes J. Present yourself! by MHC class I and MHC class II molecules. Trends Immunol 2016;37:724-37.

11 Bukur J, Jasinski S, Seliger B. The role of classical and nonclassical HLA class I antigens in human tumors. Semin Cancer Biol 2012;22:350-8. 
12 Friedrich M, Jasinski-Bergner S, Lazaridou M-F, et al. TumorInduced escape mechanisms and their association with resistance to checkpoint inhibitor therapy. Cancer Immunol Immunother 2019;68:1689-700.

13 Jasinski-Bergner S, Stoehr C, Bukur J, et al. Clinical relevance of miR-mediated HLA-G regulation and the associated immune cell infiltration in renal cell carcinoma. Oncoimmunology 2015;4:e1008805.

14 Seliger B, Jasinski-Bergner S, Quandt D, et al. HLA-E expression and its clinical relevance in human renal cell carcinoma. Oncotarget 2016;7:67360-72.

15 Ghadially H, Brown L, Lloyd C, et al. MHC class I chain-related protein $A$ and $B$ (MICA and $\mathrm{MICB}$ ) are predominantly expressed intracellularly in tumour and normal tissue. $\mathrm{Br} \mathrm{J}$ Cancer 2017; 116:1208-17.

16 Dassa L, Seidel E, Oiknine-Djian E, et al. The human cytomegalovirus protein UL148A downregulates the NK cell-activating ligand MICA to avoid NK cell attack. J Virol 2018;92:e00162-18.

17 Schmiedel D, Tai J, Levi-Schaffer F, et al. Human herpesvirus 6B downregulates expression of activating ligands during lytic infection to escape elimination by natural killer cells. J Virol 2016;90:9608-17.

18 Bauman Y, Mandelboim O. Microrna based immunoevasion mechanism of human polyomaviruses. RNA Biol 2011;8:591-4.

19 Bauman $Y$, Nachmani D, Vitenshtein A, et al. An identical miRNA of the human $\mathrm{JC}$ and $\mathrm{BK}$ polyoma viruses targets the stress-induced ligand ULBP3 to escape immune elimination. Cell Host Microbe 2011;9:93-102.

20 Mogensen TH, Paludan SR. Molecular pathways in virus-induced cytokine production. Microbiol Mol Biol Rev 2001;65:131-50.

21 Whitley RJ. Herpesviruses, 1996.

22 Owen DJ, Crump CM, Graham SC. Tegument assembly and secondary envelopment of alphaherpesviruses. Viruses 2015;7:5084-114

23 Rafailidis PI, Mourtzoukou EG, Varbobitis IC, et al. Severe cytomegalovirus infection in apparently immunocompetent patients: a systematic review. Virol J 2008;5:47.

24 Sehrawat S, Kumar D, Rouse BT. Herpesviruses: harmonious pathogens but relevant cofactors in other diseases? Front Cell Infect Microbiol 2018;8:177.

25 Naqvi AR, Shango J, Seal A, et al. Herpesviruses and microRNAs: new pathogenesis factors in oral infection and disease? Front Immunol 2018;9:2099.

26 Tang S, Bertke AS, Patel A, et al. Herpes simplex virus 2 microRNA miR-H6 is a novel latency-associated transcript-associated microRNA, but reduction of its expression does not influence the establishment of viral latency or the recurrence phenotype. J Virol 2011;85:4501-9.

27 Barbu MG, Condrat CE, Thompson DC, et al. Microrna involvement in signaling pathways during viral infection. Front Cell Dev Biol 2020;8:143.

28 Kloetzel PM, Ossendorp F. Proteasome and peptidase function in MHC-class-I-mediated antigen presentation. Curr Opin Immunol 2004;16:76-81.

29 Ferrington DA, Gregerson DS. Immunoproteasomes: structure, function, and antigen presentation. Prog Mol Biol Trans/ Sci 2012;109:75-112.

30 McCarthy MK, Weinberg JB. The immunoproteasome and viral infection: a complex regulator of inflammation. Front Microbiol 2015;6:21.

31 Benitez R, Godelaine D, Lopez-Nevot MA, et al. Mutations of the beta2-microglobulin gene result in a lack of HLA class I molecules on melanoma cells of two patients immunized with MAGE peptides. Tissue Antigens 1998;52:520-9.

32 Feenstra M, Rozemuller E, Duran K, et al. Mutation in the beta $2 \mathrm{M}$ gene is not a frequent event in head and neck squamous cell carcinomas. Hum Immunol 1999;60:697-706.

33 Chen HL, Gabrilovich D, Tampé R, et al. A functionally defective allele of TAP1 results in loss of MHC class I antigen presentation in a human lung cancer. Nat Genet 1996;13:210-3.

34 Ritz U, Drexler I, Sutter D, et al. Impaired transporter associated with antigen processing (TAP) function attributable to a single amino acid alteration in the peptide TAP subunit TAP1. J Immunol 2003;170:941-6.

35 York IA, Roop C, Andrews DW, et al. A cytosolic herpes simplex virus protein inhibits antigen presentation to CD8+ T lymphocytes. Cell 1994;77:525-35.

36 Røder G, Geironson L, Bressendorff I, et al. Viral proteins interfering with antigen presentation target the major histocompatibility complex class I peptide-loading complex. $J$ Virol 2008;82:8246-52.
37 Abendroth A, Lin I, Slobedman B, et al. Varicella-Zoster virus retains major histocompatibility complex class I proteins in the Golgi compartment of infected cells. J Virol 2001;75:4878-88.

38 Hislop AD, Ressing ME, van Leeuwen D, et al. A CD8+ T cell immune evasion protein specific to Epstein-Barr virus and its close relatives in old World primates. J Exp Med 2007;204:1863-73.

39 Zeidler R, Eissner G, Meissner P, et al. Downregulation of TAP1 in $\mathrm{B}$ lymphocytes by cellular and Epstein-Barr virus-encoded interleukin-10. Blood 1997;90:2390-7.

40 Zuo J, Currin A, Griffin BD, et al. The Epstein-Barr virus G-proteincoupled receptor contributes to immune evasion by targeting $\mathrm{MHC}$ class I molecules for degradation. PLoS Pathog 2009;5:e1000255.

41 Rowe M, Glaunsinger B, van Leeuwen D, et al. Host shutoff during productive Epstein-Barr virus infection is mediated by BGLF5 and may contribute to immune evasion. Proc Natl Acad Sci U S A 2007;104): :3366-71.

42 Levitskaya J, Sharipo A, Leonchiks A, et al. Inhibition of Ubiquitin/ proteasome-dependent protein degradation by the Gly-Ala repeat domain of the Epstein-Barr virus nuclear antigen 1. Proc Natl Acad Sci U S A 1997:94:12616-21.

43 Quinn LL, Williams LR, White C, et al. The missing link in EpsteinBarr virus immune evasion: the BDLF3 gene induces ubiquitination and downregulation of major histocompatibility complex class I (MHC-I) and MHC-II. J Virol 2016;90:356-67.

44 Hewitt EW, Gupta SS, Lehner PJ. The human cytomegalovirus gene product US6 inhibits ATP binding by TAP. Embo J 2001;20:387-96.

45 Park B, Kim Y, Shin J, et al. Human cytomegalovirus inhibits tapasin-dependent peptide loading and optimization of the MHC class I peptide cargo for immune evasion. Immunity 2004;20:71-85.

46 Furman MH, Dey N, Tortorella D, et al. The human cytomegalovirus US10 gene product delays trafficking of major histocompatibility complex class I molecules. J Virol 2002;76:11753-6.

47 Wiertz EJ, Jones TR, Sun L, et al. The human cytomegalovirus US11 gene product dislocates MHC class I heavy chains from the endoplasmic reticulum to the cytosol. Cell 1996;84:769-79.

48 Wiertz EJ, Tortorella D, Bogyo M, et al. Sec61-mediated transfer of a membrane protein from the endoplasmic reticulum to the proteasome for destruction. Nature 1996;384:432-8.

49 Urban S, Textoris-Taube K, Reimann B, et al. The efficiency of human cytomegalovirus pp65 ${ }_{(495-503)} \mathrm{CD} 8^{+} \mathrm{T}$ cell epitope generation is determined by the balanced activities of cytosolic and endoplasmic reticulum-resident peptidases. J Immunol 2012;189:529-38.

50 Grundy JE, McKeating JA, Ward PJ, et al. Beta 2 microglobulin enhances the infectivity of cytomegalovirus and when bound to the virus enables class I HLA molecules to be used as a virus receptor. J Gen Virol 1987;68:793-803.

51 Hudson AW, Blom D, Howley PM, et al. The ER-lumenal domain of the HHV-7 immunoevasin U21 directs class I MHC molecules to lysosomes. Traffic 2003;4:824-37.

52 Coscoy L, Ganem D. Kaposi's sarcoma-associated herpesvirus encodes two proteins that block cell surface display of MHC class I chains by enhancing their endocytosis. Proc Natl Acad Sci U S A 2000:97:8051-6.

$53 \mathrm{Kwun} \mathrm{HJ}$, da Silva SR, Qin H, et al. The central repeat domain 1 of Kaposi's sarcoma-associated herpesvirus (KSHV) latency associated-nuclear antigen 1 (LANA1) prevents cis MHC class I peptide presentation. Virology 2011;412:357-65.

54 Bartel DP. Micrornas: genomics, biogenesis, mechanism, and function. Cell 2004;116:281-97.

55 Nielsen AF, Gloggnitzer J, Martinez J. Micrornas cross the line: the battle for mRNA stability enters the coding sequence. Mol Cell 2009;35:139-40.

56 Chan S-P, Slack FJ. microRNA-Mediated silencing inside P-bodies. RNA Biol 2006;3:97-100.

57 Di Leva G, Garofalo M, Croce CM. Micrornas in cancer. Annu Rev Pathol 2014;9:287-314

58 Mullany LE, Herrick JS, Wolff RK, et al. Microrna seed region length impact on target messenger RNA expression and survival in colorectal cancer. PLoS One 2016;11:e0154177.

59 Jasinski-Bergner S, Mandelboim O, Seliger B. The role of microRNAs in the control of innate immune response in cancer. $J$ Natl Cancer Inst 2014:106:dju257.

60 Stark TJ, Arnold JD, Spector DH, et al. High-resolution profiling and analysis of viral and host small RNAs during human cytomegalovirus infection. J Virol 2012;86:226-35.

61 Skalsky RL, Cullen BR. Viruses, microRNAs, and host interactions. Annu Rev Microbiol 2010;64:123-41.

62 Bondada MS, Yao Y, Nair V. Multifunctional miR-155 pathway in avian oncogenic virus-induced neoplastic diseases. Noncoding RNA 2019;5:24. 
63 Linnstaedt SD, Gottwein E, Skalsky RL, et al. Virally induced cellular microRNA miR-155 plays a key role in B-cell immortalization by Epstein-Barr virus. J Virol 2010;84:11670-8.

64 Wood CD, Carvell T, Gunnell A, et al. Enhancer control of microRNA miR-155 expression in Epstein-Barr virus-infected B cells. J Virol 2018;92:e00716-8.

65 Cai L, Ye Y, Jiang Q, et al. Epstein-Barr virus-encoded microRNA BART1 induces tumour metastasis by regulating PTENdependent pathways in nasopharyngeal carcinoma. Nat Commun 2015;6:7353

66 Hooykaas MJG, van Gent M, Soppe JA, et al. Ebv microRNA BART16 suppresses type I IFN signaling. J Immunol 2017;198:4062-73.

67 O'Hara AJ, Wang L, Dezube BJ, et al. Tumor suppressor microRNAs are underrepresented in primary effusion lymphoma and Kaposi sarcoma. Blood 2009;113:5938-41.

68 Jurak I, Silverstein LB, Sharma M, et al. Herpes simplex virus is equipped with RNA- and protein-based mechanisms to repress expression of ATRX, an effector of intrinsic immunity. J Virol 2012;86:10093-102.

69 Pratt ZL, Kuzembayeva M, Sengupta S, et al. The microRNAs of Epstein-Barr virus are expressed at dramatically differing levels among cell lines. Virology 2009;386:387-97.

70 Wang M, Yu F, Wu W, et al. Epstein-Barr virus-encoded microRNAs as regulators in host immune responses. Int $\mathrm{J}$ Biol Sci 2018;14:565-76.

71 Albanese M, Tagawa T, Bouvet M, et al. Epstein-Barr virus microRNAs reduce immune surveillance by virus-specific CD8+ T cells. Proc Natl Acad Sci U S A 2016;113:E6467-75.

$72 \mathrm{Kim} \mathrm{S}$, Lee S, Shin J, et al. Human cytomegalovirus microRNA miR-US4-1 inhibits CD8(+) T cell responses by targeting the aminopeptidase ERAP1. Nat Immunol 2011;12:984-91.

73 Mégret F, Prehaud C, Lafage M, et al. Modulation of HLA-G and HLA-E expression in human neuronal cells after rabies virus or herpes virus simplex type 1 infections. Hum Immunol 2007;68:294-302.

74 Lemaoult J, Zafaranloo K, Le Danff C, et al. HLA-G up-regulates ILT2, ILT3, ILT4, and KIR2DL4 in antigen presenting cells, NK cells, and T cells. Faseb $J$ 2005;19:1-23.

75 Braud VM, Allan DS, O'Callaghan CA, et al. HLA-E binds to natural killer cell receptors CD94/NKG2A, B and C. Nature 1998;391:795-9.

76 Jasinski-Bergner S, Reches A, Stoehr C, et al. Identification of novel microRNAs regulating HLA-G expression and investigating their clinical relevance in renal cell carcinoma. Oncotarget 2016;7:26866-78

77 Nachmani D, Zimmermann A, Oiknine Djian E, et al. Microrna editing facilitates immune elimination of HCMV infected cells. PLOS Pathog 2014;10:e1003963.

78 Patel M, Vlahava V-M, Forbes SK, et al. HCMV-Encoded NK Modulators: Lessons From in vitro and in vivo Genetic Variation. Front Immunol 2018;9:2214.

79 Chentoufi AA, Kritzer E, Tran MV, et al. The herpes simplex virus 1 latency-associated transcript promotes functional exhaustion of virus-specific CD8+ T cells in latently infected trigeminal ganglia: a novel immune evasion mechanism. J Virol 2011;85:9127-38.

80 Schönrich G, Raftery MJ. The PD-1/PD-L1 axis and virus infections: a delicate balance. Front Cell Infect Microbiol 2019;9:207.

81 Méndez-Samperio P, Hernandez M, Ayala HE. Induction of transforming growth factor-beta 1 production in human cells by herpes simplex virus. J Interferon Cytokine Res 2000;20:273-80.

82 Guan Z, Song B, Liu F, et al. TGF- $\beta$ induces HLA-G expression through inhibiting miR-152 in gastric cancer cells. J Biomed Sci 2015;22:107.

83 Schmiedel D, Mandelboim O. Nkg2D Ligands-Critical targets for cancer immune escape and therapy. Front Immunol 2018;9:2040.

84 Conejo-Garcia JR, Benencia F, Courrèges MC, et al. Letal, a tumor-associated NKG2D immunoreceptor ligand, induces activation and expansion of effector immune cells. Cancer Biol Ther 2003;2:446-51.

85 Stern-Ginossar N, Mandelboim O. An integrated view of the regulation of NKG2D ligands. Immunology 2009;128:1-6.

86 Bauer S, Groh V, Wu J, et al. Activation of NK cells and T cells by NKG2D, a receptor for stress-inducible MICA. Science 1999;285:727-9.

87 Schepis D, D'Amato M, Studahl M, et al. Herpes simplex virus infection downmodulates NKG2D ligand expression. Scand $J$ Immunol 2009;69:429-36.

88 Campbell TM, McSharry BP, Steain M, et al. Varicella-Zoster virus and herpes simplex virus 1 differentially modulate NKG2D ligand expression during productive infection. J Virol 2015;89:7932-43.
89 Rancan C, Schirrmann L, Hüls C, et al. Latent membrane protein LMP2A impairs recognition of EBV-infected cells by CD8+ T cells. PLoS Pathog 2015;11:e1004906.

90 Zöller T, Wittenbrink M, Hoffmeister M, et al. Cutting an NKG2D ligand short: cellular processing of the peculiar human NKG2D ligand ULBP4. Front Immunol 2018;9:620.

$91 \mathrm{Wu} J$, Chalupny NJ, Manley TJ, et al. Intracellular retention of the MHC class I-related chain B ligand of NKG2D by the human cytomegalovirus UL16 glycoprotein. J Immunol 2003;170:4196-200.

92 Chalupny NJ, Rein-Weston A, Dosch S, et al. Down-Regulation of the NKG2D ligand MICA by the human cytomegalovirus glycoprotein UL142. Biochem Biophys Res Commun 2006;346:175-81.

93 Bennett NJ, Ashiru O, Morgan FJE, et al. Intracellular sequestration of the NKG2D ligand ULBP3 by human cytomegalovirus. J Immunol 2010;185:1093-102.

94 Fielding CA, Aicheler R, Stanton RJ, et al. Two novel human cytomegalovirus NK cell evasion functions target MICA for lysosomal degradation. PLoS Pathog 2014;10:e1004058.

95 Schneider CL, Hudson AW. The human herpesvirus-7 (HHV-7) U21 immunoevasin subverts NK-mediated cytoxicity through modulation of MICA and MICB. PLoS Pathog 2011;7:e1002362.

96 Thomas M, Boname JM, Field S, et al. Down-Regulation of NKG2D and NKp80 ligands by Kaposi's sarcoma-associated herpesvirus K5 protects against NK cell cytotoxicity. Proc Natl Acad Sci U S A 2008;105:1656-61.

97 lizasa H, Wulff B-E, Alla NR, et al. Editing of Epstein-Barr virus-encoded BART6 microRNAs controls their dicer targeting and consequently affects viral latency. $J$ Biol Chem 2010;285:33358-70.

98 Enk J, Levi A, Weisblum Y, et al. Hsv1 microRNA modulation of GPI anchoring and downstream immune evasion. Cell Rep 2016:17:949-56.

99 Nachmani D, Stern-Ginossar N, Sarid R, et al. Diverse herpesvirus microRNAs target the stress-induced immune ligand MICB to escape recognition by natural killer cells. Cell Host Microbe 2009;5:376-85.

100 Wong T-S, Chen S, Zhang M-J, et al. Epstein-Barr virus-encoded microRNA BART7 downregulates major histocompatibility complex class I chain-related peptide $A$ and reduces the cytotoxicity of natural killer cells to nasopharyngeal carcinoma. Oncol Lett 2018;16:2887-92

101 Nachmani D, Lankry D, Wolf DG, et al. The human cytomegalovirus microRNA miR-UL112 acts synergistically with a cellular microRNA to escape immune elimination. Nat Immunol 2010;11:806-13.

102 Trinchieri G. Interleukin-12: a proinflammatory cytokine with immunoregulatory functions that bridge innate resistance and antigen-specific adaptive immunity. Annu Rev Immunol 1995:13:251-76.

103 Sekiyama KD, Yoshiba M, Thomson AW. Circulating proinflammatory cytokines (IL-1 beta, TNF-alpha, and IL-6) and IL-1 receptor antagonist (IL-1ra) in fulminant hepatic failure and acute hepatitis. Clin Exp Immunol 1994;98:71-7.

104 Dinarello CA. II-18: a TH1-inducing, proinflammatory cytokine and new member of the IL-1 family. J Allergy Clin Immunol 1999;103:11-24.

105 Duvallet E, Semerano L, Assier E, et al. Interleukin-23: a key cytokine in inflammatory diseases. Ann Med 2011;43:503-11.

106 Zlotnik A, Yoshie O. The chemokine superfamily revisited. Immunity 2012;36:705-16.

107 Mogensen TH, Melchjorsen J, Malmgaard L, et al. Suppression of proinflammatory cytokine expression by herpes simplex virus type 1. J Virol 2004;78:5883-90.

108 Morrison TE, Mauser A, Wong A, et al. Inhibition of IFN-gamma signaling by an Epstein-Barr virus immediate-early protein. Immunity 2001;15:787-99.

109 Wong NHM, Yuen K-S, Chan C-P, et al. Suppression of IFN- $\beta$ production by Epstein-Barr virus lytic transactivator Zta. J Immunol 2017; 198:214.15.

110 Chuang H-C, Lay J-D, Chuang S-E, et al. Epstein-Barr virus (EBV) latent membrane protein-1 down-regulates tumor necrosis factoralpha (TNF-alpha) receptor-1 and confers resistance to TNF-alphainduced apoptosis in T cells: implication for the progression to T-cell lymphoma in ebv-associated hemophagocytic syndrome. Am J Pathol 2007;170:1607-17.

111 Herbst H, Foss HD, Samol J, et al. Frequent expression of interleukin- 10 by Epstein-Barr virus-harboring tumor cells of Hodgkin's disease. Blood 1996;87:2918-29.

112 Skinner CM, Ivanov NS, Barr SA, et al. An Epstein-Barr virus microRNA blocks interleukin-1 (IL-1) signaling by targeting IL-1 receptor 1. J Virol 2017;91:e00530-17. 
113 Miller DM, Zhang Y, Rahill BM, et al. Human cytomegalovirus inhibits IFN-alpha-stimulated antiviral and immunoregulatory responses by blocking multiple levels of IFN-alpha signal transduction. J Immunol 1999;162:6107-13.

114 Choi HJ, Park A, Kang S, et al. Human cytomegalovirus-encoded US9 targets MAVS and sting signaling to evade type I interferon immune responses. Nat Commun 2018:9:125.

115 Baillie J, Sahlender DA, Sinclair JH. Human cytomegalovirus infection inhibits tumor necrosis factor alpha (TNF-alpha) signaling by targeting the 55-kilodalton TNF-alpha receptor. $J$ Virol 2003;77:7007-16.

116 Feng L, Sheng J, Vu G-P, et al. Human cytomegalovirus UL23 inhibits transcription of interferon- $\gamma$ stimulated genes and blocks antiviral interferon- $\gamma$ responses by interacting with human $\mathrm{N}-\mathrm{myc}$ interactor protein. PLoS Pathog 2018;14:e1006867.

117 Pontejo SM, Murphy PM, Pease JE. Chemokine subversion by human herpesviruses. J Innate Immun 2018;10:465-78.

118 Wang D, Bresnahan W, Shenk T. Human cytomegalovirus encodes a highly specific RANTES decoy receptor. Proc Natl Acad Sci U S A 2004;101:16642-7.

119 Pleskoff O, Tréboute $\mathrm{C}$, Brelot A, et al. Identification of a chemokine receptor encoded by human cytomegalovirus as a cofactor for HIV1 entry. Science 1997;276:1874-8.

120 Sozzani S, Luini W, Bianchi G, et al. The viral chemokine macrophage inflammatory protein-II is a selective Th2 chemoattractant. Blood 1998;92:4036-9.

121 Gregory SM, Wang L, West JA, et al. Latent Kaposi's sarcomaassociated herpesvirus infection of monocytes downregulates expression of adaptive immune response costimulatory receptors and proinflammatory cytokines. J Virol 2012;86:3916-23.

122 Jensen K, Patel A, Larin A, et al. Human herpes simplex viruses in benign and malignant thyroid tumours. J Pathol 2010;221:193-200.
123 Thomas F, Elguero E, Brodeur J, et al. Herpes simplex virus type 2 and cancer: a medical geography approach. Infect Genet Evol 2011;11:1239-42.

124 Haverkos H, Rohrer M, Pickworth W. The cause of invasive cervical cancer could be multifactorial. Biomed Pharmacother 2000:54:54-9.

125 Golais F, Mrázová V. Human alpha and beta herpesviruses and cancer: passengers or foes? Folia Microbiol 2020;65:439-49.

126 Wales SQ, Li B, Laing JM, et al. The herpes simplex virus type 2 gene ICP10PK protects from apoptosis caused by nerve growth factor deprivation through inhibition of caspase-3 activation and XIAP up-regulation. J Neurochem 2007;103:365-79.

127 Malavige GN, Rohanachandra LT, Jones L, et al. IE63-specific T-cell responses associate with control of subclinical varicella zoster virus reactivation in individuals with malignancies. $\mathrm{Br} J$ Cancer 2010;102:727-30.

128 Alibek K, Baiken Y, Kakpenova A, et al. Implication of human herpesviruses in oncogenesis through immune evasion and supression. Infect Agent Cancer 2014;9:3

129 Raab-Traub N. Novel mechanisms of EBV-induced oncogenesis. Curr Opin Virol 2012;2:453-8.

130 Loutfy SA, Fawzy M, El-Wakil M, et al. Presence of human herpes virus 6 (HHV6) in pediatric lymphomas: impact on clinical course and association with cytomegalovirus infection. Virol $J$ 2010;7:287.

131 Seror E, Coquerel B, Gautheret-Dejean A, et al. Quantitation of human herpes virus 6 genome in children with acute lymphoblastic leukemia. J Med Virol 2008;80:689-93.

132 Friborg J, Kong W, Hottiger MO, et al. P53 inhibition by the LANA protein of KSHV protects against cell death. Nature 1999;402:889-94.

133 Cheng EH, Nicholas J, Bellows DS, et al. A Bcl-2 homolog encoded by Kaposi sarcoma-associated virus, human herpesvirus 8 , inhibits apoptosis but does not heterodimerize with Bax or Bak. Proc Nat Acad Sci U S A 1997;94:690-4. 